\title{
THE MARGINAL ANALYSIS AS A METHOD FOR RESEARCH AND MANAGEMENT OF OPERATING COSTS IN RAIL FREIGHT TRANSPORT
}

\author{
Emiliya Vaysilova \\ “Todor Kableshkov" University of Transport, Sofia, Bulgaria
}

CMESTE

JEL Category: L92, M11

\begin{abstract}
It is a characteristic of the transport sector companies that operate in a highly competitive internal and external market environment. To survive and thrive in such an environment, they should strive for continuous improvement in the efficiency of their operations. An important role in achieving such an intention is to carry out constant monitoring and analysis of ongoing business processes in the enterprise, as well as to study their impact in the formation of its financial results. Besides, one of the main focuses of management is the monitoring and research of enterprise costs. The study of costs in freight rail transport enterprises is a determining factor for the elaboration of management decisions tailored to the economic reality and economic conjuncture. This raises the need for a comprehensive and in-depth cost analysis - based on the numerous schemes of systematization and models of functional dependencies between costs and other economic objects. In this regard, the purpose of conducting a cost analysis is to identify the changes that have occurred and to seek opportunities to optimize them. The great importance of research and analysis of costs also stems from the fact that their value, structure, and dynamics depend on the financial result. Any relative cost reduction has a positive impact on the financial result. The actuality of the research and analysis of operating costs in rail transport is driven by the fact that rail freight is faced with an extremely serious problem, such as increasing competition from other modes of transport. This paper examines one of the many management methods for cost research - the marginal cost method. The theoretical aspects of the method are briefly presented, as well as its practical application, which is illustrated by an example.
\end{abstract}

Keywords: costing, estimation, databases, decision support, management effectiveness, transportation, rail, marginal analysis.

Address of the corresponding author:

Emiliya Vaysilova

㪯" emvais@abv.bg

\section{INTRODUCTION}

The study of costs in freight rail transport enterprises is a determining factor for the elaboration of management decisions tailored to the economic reality and economic situation. This 
raises the need for a comprehensive and in-depth cost analysis - based on the numerous schemes of systematization and models of functional dependencies between costs and other economic objects.

The main purpose of cost analysis is to identify the changes that have occurred and on this base to seek opportunities to optimize them. The great importance of research and analysis of costs also stems from the fact that their value, structure, and dynamics depend on the financial result. Any relative cost reduction has a positive impact on the financial result.

The costs associated with the implementation of the main activity (transport activity) in freight rail transport are commonly referred to as operating costs. The use of the term operating costs (rather than production costs) is necessitated by the fact that they are highly expressed in rail transport. In practice, the transport process involves a wide range of activities. Operating costs are divided into two main groups: conditional fixed operating costs and variable technological costs. Costs in each of the above groups are also stated by economic nature.

In the economic literature, there are various management methods for the cost study. The purpose of this study is to demonstrate the capabilities of one of these methods, the marginal cost method, in managing freight costs of freight rail transport. In this connection, the subject of the study is the operating costs of a hypothetical freight transport undertaking.

\section{THE ESSENCE AND PRINCIPLES OF EFFECT OF MARGINAL ANALYSIS}

At the heart of this analysis is the concept of the relationship between total, average, and marginal costs. These costs are crucial in the decisionmaking process of managers. The essential thing about applying the marginal cost method is that in the end, all three types of costs are functions of the quantity of output produced. At the same time, the existing ratio between these costs is essential. On the one hand, total costs are the sum (integral) of prior marginal costs. On the other hand, there are the following relationships between average and marginal cost: if the average costs increase, the marginal costs are greater than them; if average costs do not change, then they are equal to marginal costs; if average costs decrease, marginal costs are lower than them (Yonkova, 2006).

The subject of marginal analysis, similar to that of the critical point analysis, is the Cost-VolumeProfit relationship. In this case, the relationship between these indicators is examined in terms of how much the total costs, total revenues, and total profits change as a result of the increase of sales with unit production. However, there is a significant difference between these two methods of investigation. In the analysis of the critical point, a linear function of the Cost-Volume-Profit relationship is applied, which reveals that maximum revenues are realized when making maximum sales. In the marginal analysis, a nonlinear cost-volume-profit relationship is applied, which shows that, once a certain, high volume of sales is reached, the total cost exceeds the total revenue. This model produces two critical points. According to marginal analysis, the optimum production volume that guarantees maximum profit is achieved when marginal revenue equals marginal cost.

Marginal analysis is used to optimize business activity by several elements - operating costs, output, profit, prices. This analysis is based on economic theoretical backgrounds known in the economic literature (Pirimova, 1995), (Rakarova, 2008), (Savov \& Mirkovich, Ikonomiks, 1998), (Savov \& Sotirova, Mikroikonomika, 1998):

- Variable costs increase at the same rate as total costs increase - after the start of the activity, the difference between their values determines the number of marginal costs.

- The marginal cost curve has a U-shape, which indicates that they initially decrease and increase after a certain moment.

- The marginal cost curve breaks the average and average variable cost curves to their minimums. Before these minimums, the slopes of the curves of average total and average variable costs are negative, indicating that each additional unit of production will lead to a decrease in average total and average variable costs. After this 
point, the slopes become positive and costs start to increase.

- The level of marginal cost is always equal to the slope of the variable cost curve.

- The point at which the variable cost curve changes its sign and begins to grow is a breaking point and corresponds to the minimum of marginal cost. This is the point at which the total cost curve also changes its slope.

- The average total costs are divided by average fixed and average variable costs. The relation between these costs and the volume of production is the following: the average fixed costs decrease with the production volume increases, while the average variable costs decrease to a certain level and then begin to increase.

- The U-shaped model of the curves of the mean total, average variables, and marginal costs is influenced by the law of diminishing returns.

- In the short run, production can only adapt to market demand through variable costs that depend on production volume.

The functional dependence of variable costs on the volume of transport production is the basis for building the model of marginal costs.

\section{PRACTICAL IMPLEMENTATION OF MARGINAL ANALYSIS}

The main purpose of the model construction is to show (analytically and graphically) characteristic points, showing minimal costs with optimal production volume. The model can identify the potential capabilities of the company and in this regard to develop adequate management decisions.

To demonstrate the marginal analysis, we will look at a hypothetical freight rail transport company, "ABC" Ltd. It is characteristic of the enterprises in this sector that they operate within the transport market together with many similar enterprises (including automotive ones). These undertakings cannot influence the market price. This indicates that the market structure is close to perfect competition. In such a market, the following principles of behavior apply:
- $\quad$ In the short run, to maximize profit, at the unit price (marginal revenue) above average total costs, or to minimize loss, at a price below average total costs (but above average variables), the enterprise should aim for the following: - marginal costs should be equal to marginal revenues, or at least very close; marginal profit should be close to zero; - total revenues should be highest, observing the first two conditions;

- The volume of production should be within the boundary between the intersections' points of the marginal costs curve with the curves of marginal revenues and the average variable costs.

- If the imposed market price of production is lower than the average total costs, one option is to leave the market segment. In such a situation, the enterprise suffers a loss that is justified only if it has a large fixed capital. In this case, the enterprise produces certain volumes and can cover its variable costs and some of its fixed costs. Such behavior is inherent for companies that expect to compensate for the accumulated losses in future periods.

- The point at which the marginal costs curve intersects the average variable costs curve is critical and is known as the sector escape point. If the selling price is below this point, there is no alternative for the undertaking other than leaving the sector.

The marginal analysis model is being built for a market with perfect competition. This contributes to its versatility. Some assumptions and limitations are made in the model implementation (Byrns \& Stone, 1992):

- there are no barriers to access and exit for all interested operators in the sector concerned.

- the individual company has no control over the price, i.e. the market is dominated by a single price.

- individual companies have equal access to the price and volume information that is traded on the individual product markets. This means that the cost curves of all businesses are identical.

- the demand curve is eliminated because demand exceeds supply. The demand curve 
for each undertaking is horizontal (with perfect elasticity).

The model enables the following tasks to be solved:

- determining the optimal level of costs when the enterprise is unable to influence production volumes and sales prices.

- $\quad$ determining the volume of production at which the total profit is maximized.

- setting a price level (for a given volume of production) that will maximize profits.

The steps to follow in building the model are as follows:

\section{Table 1. Cost data and volume of shipments of "ABC" Ltd.}

\begin{tabular}{|c|c|c|c|c|}
\hline Year & $\begin{array}{c}\text { Fixed } \\
\text { costs (a) }\end{array}$ & costs (b) & $\begin{array}{c}\text { Total operating } \\
\text { costs (TC) } \\
\text { (thousands of } \\
\text { BGN) }\end{array}$ & $\begin{array}{c}\text { Manufactured } \\
\text { products (mil. } \\
\text { tkm) (q) }\end{array}$ \\
\hline 1 & 2 & 3 & $4(2+3)$ & 5 \\
\hline 2014 & 71939 & 192598 & 264537 & 5214 \\
\hline 2015 & 70529 & 188505 & 259034 & 5166 \\
\hline 2016 & 74063 & 190985 & 265048 & 5227 \\
\hline 2017 & 79329 & 208424 & 287753 & 4711 \\
\hline 2018 & 66782 & 185147 & 251929 & 4031 \\
\hline 2019 & 59472 & 103438 & 162910 & 2265 \\
\hline
\end{tabular}

Table 2. Average cost values

\begin{tabular}{|c|r|r|r|}
\hline Year & Average fixed costs & Average variable & Average total cost \\
& $\mathrm{Ca}(\mathbf{a} / \mathbf{q})$ & costs $\mathbf{C b}$ (b/q) & CTC (TC/q) \\
\hline 2014 & 13.79727656 & 36.93862677 & 50.73590334 \\
\hline 2015 & 13.65253581 & 36.48954704 & 50.14208285 \\
\hline 2016 & 14.16931318 & 36.53816721 & 50.70748039 \\
\hline 2017 & 16.83909998 & 44.24198684 & 61.08108682 \\
\hline 2018 & 16.56710494 & 45.93078641 & 62.49789134 \\
\hline 2019 & 26.25695364 & 45.66799117 & 71.92494481 \\
\hline
\end{tabular}

\section{Step two: Establishing links between production volume and cost types:}

- $\quad$ between total operating costs and production volume.

- between average variable costs and production volume.

- between marginal costs and production volume.

Well-known in economic theory is the fact that when the cost model changes (from linear to nonlinear) for the needs of internal company analysis, they are best described by a second-

\section{Step one: Gathering statistics for:}

- $\quad$ Total operating costs - TC;

- $\quad$ Fixed operating costs $-a$;

- Variable operating costs $-b$;

- Average total costs $-c_{T C}$;

- Average fixed costs - $c_{a}$;

- Average variable costs $-c_{b}$;

- marginal costs $-c_{m}$;

- $\quad$ the volume of production for the study period $-q$.

This information, for the company "ABC" Ltd, for six years, is presented in Table 1 and Table 2. 
Here $\beta_{0}$ is a free member and corresponds to the fixed costs, $\beta_{1}$ and $\beta_{2}$ are the coefficients of the regression model.

The parameters of these functions are determined using the least-squares method, and the built-in Table 3. Function parameter values (1), (2) u (3) statistical functions of the specialized software product STATISTICA-7 are used to facilitate the calculation process. The results for these parameters are summarized in Table 3.

\begin{tabular}{|c|c|l|l|}
\hline Dependent & $\boldsymbol{\beta}_{0}$ & $\boldsymbol{\beta}_{1}$ & $\boldsymbol{\beta}_{2}$ \\
\hline $\boldsymbol{c}_{T C}$ & 174.5838491598 & -0.0377014772 & 0.0000023596 \\
\hline $\boldsymbol{c}_{b}$ & 57.6479732517 & -0.0060797080 & 0.0000040560 \\
\hline $\boldsymbol{c}_{m}$ & 58.4546301384 & -0.0123023021 & 0.0000012115 \\
\hline
\end{tabular}

\section{Step Three: Construction of a graphical model containing two figures.}

The graphs are built on the reporting data for 2019. The secondary data in a short version needed to build the graphical model are presented in Table 4. The first figure (Fig. 1) shows the curves of the total, fixed, and variable costs. The revenue line is also depicted. The second figure (Fig. 2) presents the marginal, average total, and average variable cost curves. The marginal revenue line is also shown.

Based on the analytical and graphical results of the analysis of the marginal costs (marginal analysis), respectively, the marginal revenues of company "ABC" Ltd. the following conclusions can be drawn:

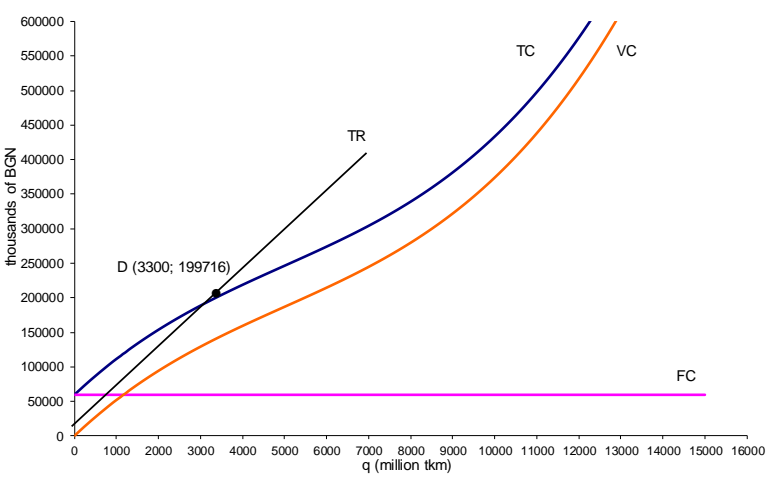

Fig. 1 General, fixed and variable cost cur

The imposed equilibrium price in the freight the rail sector is disadvantageous for the enterprise under the given conditions because for 2019 it realizes volume of production with total costs above this marginal income (the realized volume is below the critical volume of 3300 million tkm point E, Fig. 2 and point D, Fig. 1). However, in a fairly large range (to the right of point $E$ ), the average total cost of the enterprise is below the level of marginal revenue;

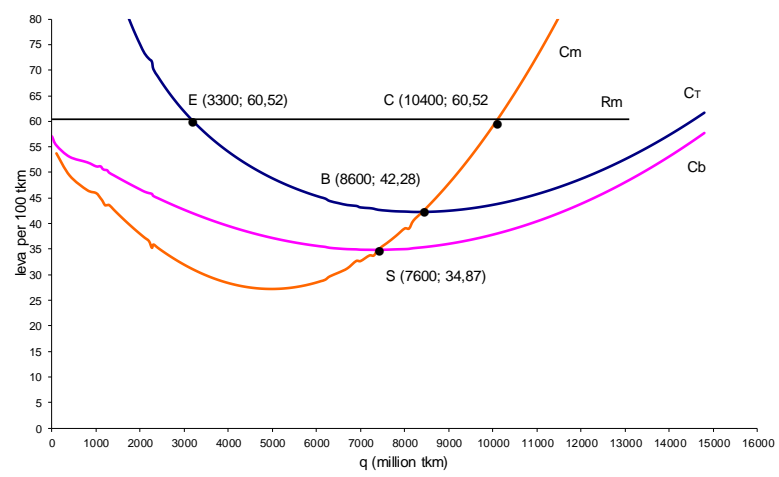

Fig. 2 Marginal, average total and average variable cost curves

$>$ Minimum average total costs are reached for the production volume of 8600 million tkm (point C - Fig. 2). To the right of this point, the average total costs are gradually increasing, but the total profit increases (the profit per unit of production decreases);

The minimum possible variable costs are achieved with a production volume of 7600 million tkm - point S, Fig. 2;

$>$ Positive value of the financial result is obtained when the volume of production exceeds 3300 million tkm - point $D$, Fig. 1 and point $F$, Fig. 2. In these points, the total revenue equals the total costs - for point $D$, respectively for point $E$ - the marginal revenue equals the average total cost. At volumes below 3300 million $\mathrm{tkm}$, the company makes losses, and at volumes above the critical one, the company makes profits;

The enterprise will receive the maximum possible profit, with a production volume of 10400 million tkm, at which marginal costs are equalized with the equilibrium price, i.e. in point C, Fig. 2. 
Table 4. Data for the construction of cost curves for marginal analysis

\begin{tabular}{|c|c|c|c|c|c|c|c|}
\hline $\begin{array}{c}\text { Production } \\
\text { volume } \\
\text { (million tkm) } \\
\end{array}$ & $\begin{array}{c}\text { Total operating } \\
\text { costs (BGN } \\
\text { thousand) } \\
\end{array}$ & $\begin{array}{c}\text { Continuous } \\
\text { operating costs } \\
\text { (BGN thousand) }\end{array}$ & \begin{tabular}{|c|}
$\begin{array}{c}\text { Variable } \\
\text { operating costs } \\
\text { (BGN thousand) }\end{array}$ \\
\end{tabular} & \begin{tabular}{|c|} 
Total unit \\
cost $(\mathrm{BGN}$ \\
per $1000 \mathrm{tkm})$ \\
\end{tabular} & $\begin{array}{c}\text { Variable cost } \\
\text { per unit (BGN } \\
\text { per } 1000 \mathrm{tkm})\end{array}$ & $\begin{array}{c}\text { Marginal } \\
\text { cost (BGN } \\
\text { thousand) } \\
\end{array}$ & \begin{tabular}{|c|} 
Marginal \\
revenue (BGN \\
per $1000 \mathrm{tkm}$ ) \\
\end{tabular} \\
\hline$q$ & $\mathrm{TC}$ & FC & VC & Ctc & $\mathrm{Cb}$ & $\mathrm{Cm}$ & $\mathbf{R m}$ \\
\hline 1 & 2 & 3 & 4 & 5 & 6 & 7 & 8 \\
\hline 0 & 59472.00 & 59472 & 0 & & 17.98 & & \\
\hline 100 & 61240.37 & 59472 & 1768.37 & 70.42 & 17.68 & 16.68 & 60.52 \\
\hline 400 & 66202.44 & 59472 & 6730.44 & 68.85 & 16.83 & 15.54 & 60.52 \\
\hline 800 & 72099.16 & 59472 & 12627.16 & 66.84 & 15.78 & 13.74 & 60.52 \\
\hline 1000 & 74778.27 & 59472 & 15306.27 & 65.87 & 15.31 & 13.40 & 60.52 \\
\hline 1100 & 76058.10 & 59472 & 16586.10 & 65.39 & 15.08 & 12.80 & 60.52 \\
\hline 1150 & 76684.04 & 59472 & 17212.04 & 65.16 & 14.97 & 12.52 & 60.52 \\
\hline 1200 & 77301.02 & 59472 & 17829.02 & 64.92 & 14.86 & 12.43 & 60.52 \\
\hline 1250 & 77909.31 & 59472 & 18437.31 & 64.69 & 14.75 & 12.25 & 60.52 \\
\hline 2900 & 94884.12 & 59472 & 35412.12 & 57.85 & 12.21 & 9.47 & 60.52 \\
\hline 3000 & 95833.47 & 59472 & 36361.47 & 57.48 & 12.12 & 9.49 & 60.52 \\
\hline 3100 & 96787.13 & 59472 & 37315.13 & 57.13 & 12.04 & 9.54 & 60.52 \\
\hline 3200 & 97747.26 & 59472 & 38275.26 & 56.78 & 11.96 & 9.60 & 60.52 \\
\hline 3300 & 98716.04 & 59472 & 39244.04 & 56.43 & 11.89 & 9.69 & 60.52 \\
\hline 3400 & 99695.62 & 59472 & 40223.62 & 56.10 & 11.83 & 9.80 & 60.52 \\
\hline 3500 & 100688.18 & 59472 & 41216.18 & 55.76 & 11.78 & 9.93 & 60.52 \\
\hline 3600 & 101695.90 & 59472 & 42223.90 & 55.44 & 11.73 & 10.08 & 60.52 \\
\hline 3700 & 102720.94 & 59472 & 43248.94 & 55.12 & 11.69 & 10.25 & 60.52 \\
\hline 3800 & 103765.46 & 59472 & 44293.46 & 54.80 & 11.66 & 10.45 & 60.52 \\
\hline 3900 & 104831.65 & 59472 & 45359.65 & 54.49 & 11.63 & 10.66 & 60.52 \\
\hline 4000 & 105921.67 & 59472 & 46449.67 & 54.19 & 11.61 & 10.90 & 60.52 \\
\hline 4100 & 107037.68 & 59472 & 47565.68 & 53.90 & 11.60 & 11.16 & 60.52 \\
\hline 5300 & 123247.52 & 59472 & 63775.52 & 50.81 & 12.03 & 15.97 & 60.52 \\
\hline 5400 & 124898.96 & 59472 & 65426.96 & 50.59 & 12.12 & 16.51 & 60.52 \\
\hline 5500 & 126606.77 & 59472 & 67134.77 & 50.38 & 12.21 & 17.08 & 60.52 \\
\hline 5600 & 128373.12 & 59472 & 68901.12 & 50.17 & 12.30 & 17.66 & 60.52 \\
\hline 5700 & 130200.19 & 59472 & 70728.19 & 49.97 & 12.41 & 18.27 & 60.52 \\
\hline 5800 & 132090.14 & 59472 & 72618.14 & 49.78 & 12.52 & 18.90 & 60.52 \\
\hline 5900 & 134045.14 & 59472 & 74573.14 & 49.59 & 12.64 & 19.55 & 60.52 \\
\hline 6000 & 136067.37 & 59472 & 76595.37 & 49.41 & 12.77 & 20.22 & 60.52 \\
\hline 6100 & 138158.98 & 59472 & 78686.98 & 49.23 & 12.90 & 20.92 & 60.52 \\
\hline 6200 & 140322.16 & 59472 & 80850.16 & 49.06 & 13.04 & 21.63 & 60.52 \\
\hline 6300 & 142559.07 & 59472 & 83087.07 & 48.89 & 13.19 & 22.37 & 60.52 \\
\hline 6500 & 147262.75 & 59472 & 87790.75 & 48.58 & 13.51 & 23.52 & 60.52 \\
\hline 8400 & 210408.35 & 59472 & 150936.35 & 46.83 & 17.97 & 42.27 & 60.52 \\
\hline 8600 & 219347.79 & 59472 & 159875.79 & 46.77 & 18.59 & 44.70 & 60.52 \\
\hline 8800 & 228790.43 & 59472 & 169318.43 & 46.73 & 19.24 & 47.21 & 60.52 \\
\hline 9000 & 238753.64 & 59472 & 179281.64 & 46.72 & 19.92 & 49.82 & 60.52 \\
\hline 9200 & 249254.77 & 59472 & 189782.77 & 46.73 & 20.63 & 52.51 & 60.52 \\
\hline 9400 & 260311.17 & 59472 & 200839.17 & 46.77 & 21.37 & 55.28 & 60.52 \\
\hline 9600 & 271940.21 & 59472 & 212468.21 & 46.83 & 22.13 & 58.15 & 60.52 \\
\hline 9800 & 284159.25 & 59472 & 224687.25 & 46.91 & 22.93 & 61.10 & 60.52 \\
\hline 10000 & 296985.63 & 59472 & 237513.63 & 47.02 & 23.75 & 64.13 & 60.52 \\
\hline 12200 & 483125.04 & 59472 & 423653.04 & 49.80 & 34.73 & 103.26 & 60.52 \\
\hline 12400 & 504593.47 & 59472 & 445121.47 & 50.20 & 35.90 & 107.34 & 60.52 \\
\hline 12600 & 526894.89 & 59472 & 467422.89 & 50.62 & 37.10 & 111.51 & 60.52 \\
\hline 12800 & 550046.65 & 59472 & 490574.65 & 51.06 & 38.33 & 115.76 & 60.52 \\
\hline 13000 & 574066.13 & 59472 & 514594.13 & 51.53 & 39.58 & 120.10 & 60.52 \\
\hline
\end{tabular}




\section{CONCLUSIONS}

Against this background, one of the short-term alternatives for company $A B C$ Ltd. is to look for ways to minimize the variable operating costs. Another alternative is to intensify its marketing research to open new markets and increase production.

In the long run, the firm can also rethink its fixed costs policy.

The application of the model for research and analysis of marginal costs, respectively marginal revenues, supports the process of forecasting total costs and revenues for the activity at different levels of production of transport production. This model provides information on the state of the enterprise, as well as information for determining the directions in which to orient the production policy.

The model also has its disadvantages, which are a consequence of the above limitations. Not including the demand curve for the entire transport market, which in practice ignores the wide variety of market conditions, creates a slight distortion of actual results. The model also does not express the need for technological restructuring.

\section{WORKS CITED}

Byrns, R., \& Stone, G. (1992). Microeconomics. New York: Harper Collins.

Pirimova, V. (1995). Mikroikonomicheska teoria. Sofia: Ratsio-90.

Rakarova, S. (2008). Ikonomika za menidzhari. Sofia: Nov bulgarski universitet.

Savov, S., \& Mirkovich, K. (1998). Ikonomiks. Sofia: Trakia-M.

Savov, S., \& Sotirova, E. (1998). Mikroikonomika. Sofia: Trakia-M.

Saykova, I., \& Todorova, S. (2000). Statisticheskoto izsledvane - Postanovka, metodi, otsenka na rezultatite. Sofia: Unikam-print.

Yonkova, B. (2006). Upravlensko schetovodstvo. Sofia: IK Romina.

Zhelezov, E. (1994). Prilozhenie na marginalnite ikonomicheski teorii pri izbor na firmena politika. Zhelezopaten transpor, 11.

Received for publication: $\quad 20.01 .2020$

Revision received: $\quad 03.05 .2020$

Accepted for publication: $\quad 01.07 .2020$

\section{How to cite this article?}

Style - APA Sixth Edition:

Vaysilova, E. (2020, July 15). The marginal analysis as a method for research and management of operating costs in rail freight transport. (Z. Cekerevac, Ed.) MEST Journal, 8(2), 184-191. doi:10.12709/mest.08.08.02.21

Style - Chicago Sixteenth Edition:

Vaysilova, Emiliya. 2020. "The marginal analysis as a method for research and management of operating costs in rail freight transport." Edited by Zoran Cekerevac. MEST Journal (MESTE) 8 (2): 184-191. doi:10.12709/mest.08.08.02.21. 
Style - GOST Name Sort:

Vaysilova Emiliya The marginal analysis as a method for research and management of operating costs in rail freight transport [Journal] // MEST Journal / ed. Cekerevac Zoran. - Belgrade Toronto : MESTE, July 15, 2020. - 2 : Vol. 8. - pp. 184-191.

Style - Harvard Anglia:

Vaysilova, E., 2020. The marginal analysis as a method for research and management of operating costs in rail freight transport. MEST Journal, 15 July, 8(2), pp. 184-191.

Style - ISO 690 Numerical Reference:

The marginal analysis as a method for research and management of operating costs in rail freight transport. Vaysilova, Emiliya. [ed.] Zoran Cekerevac. 2, Belgrade - Toronto : MESTE, July 15, 2020, MEST Journal, Vol. 8, pp. 184-191. 